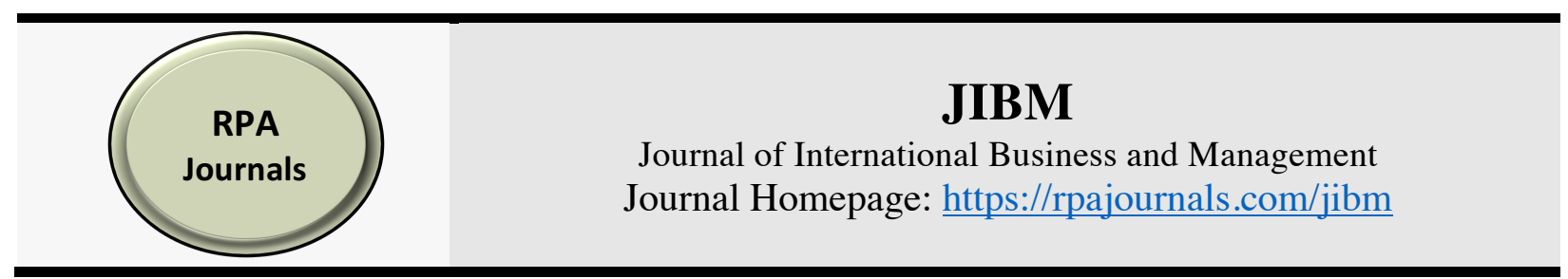

\title{
Moving from Big Data to Smart Data for Enhanced Performance, Business Efficiency, and New Business Models
}

\author{
Marcel Schramm*, \\ Mathew Shafaghi ${ }^{2}$ \\ University of Bolton, United Kingdom (UK)
}

\begin{abstract}
In recent years the use and application of data including; Big Data, AI, Intelligent Data, Forecasting, Planning, and Warehousing tools have provided businesses with significant opportunities and potential for competitive advantages. However, this is the beginning of the journey. The notion that data is used for generating intuition is gradually being rejected by organisation, and the focus is more on how to leverage the full potential of data. The term Big Data was introduced in 1980 and contains a number of different fields including messages, images, posts on social media networks, GPS signals from phones, and business data. Whilst Big Data can assist in improving performance, efficient operations, customised promotion, and new business models, the success of Big Data relies heavily on Smart Data. Smart Data first appeared in the literature in 2009 and defined as use of relevant data for supporting decision making process. Smart Data is viewed by some as a foundation for business intelligence and bring many benefits to data driven organisations including; Data Modelling, Data, Analytics, Access Control in line with data governance, and Data Aggregation. This paper provides a critical review of literature dealing with both Big Data and Smart Data with a view to recommend a conceptual framework for Smart Data Framework based on four levels of Strategy, Resources, Operations, and Design.
\end{abstract}

Keywords: Smart Data, Big Data, Business Performance, Data Analytics

*Corresponding author: Marcel Schramm; Email: marcel.schramm.s@googlemail.com

DOI: https://doi.org/10.37227/jibm-2020-02-16

\section{Introduction}

Smart data is defined as data transformed into information which feeds the decision-making and action cycle (Lafrate, 2015). This suggests that Smart Data is related to information which enable the companies to act and decide rather than to be overwhelmed with tons of data sources. As the volume of available data has significantly increased during the recent years, the discussion about how data can be used efficiently for business related areas has attracted the attention of marketers to exploit business potentials based on data knowledge. The available data gives the companies the unique chance to gain knowledge about key factors which impact business performance such as the market trends, consumer behaviour, trade partners, suppliers, and the competition (Nagle and Müller, 2017). However, the majority of companies are overwhelmed with large volume of data and do not find ways to efficiently combining the given information (Canitoa et. al., 2018) and drive the business based on the given information as this is directly with high initial costs for creating the relevant 
framework and the need for long-term headcounts to improve the data driven set up and decision making.

This paper is intended to provide a critical analysis of literature in relation to Big Data and Smart Data, how Big Data can be turned into Smart Data and how this can is connected to data driven decision making and opportunity for competitive advantage. Further existing strategic approaches to Smart Data will be analysed and the paper conclude with a conceptual framework. It is intended that the proposed framework will provide academic and practitioners with a strategy on how to best benefits from the opportunities provided by Smart Data.

\section{Literature Review}

\section{Big Data}

The term "Big Data" was first used in 1980 by Sociologist Charles Tilly (1980) who used the term as a magnitude for the term "data" in a different context. However, the first article on Big Data in the modern context was published by Mougalas in 2005. Big Data contains a large number of different fields such as messages, images, posts on social media networks, GPS signals from phones (McAfee and Brynjolfsson, 2012), historical data, business data, geographical data, and much more (Manyika, et al., 2011). According to Lohr (2012) we are in the new era of Big Data where Facebook and Google are efficiently using user search data and posts to connect them with the advertisements designed to meet their needs best. During the World Economic Forum in Swiss (2012) data was declared as a new class of economic asset comparable with gold or a new currency which underlines the importance and value of data. The use of Big Data can also improve business performance and ensure efficient operations, customized promotions (Lohr, 2012), assist in implementing new business models and establishing new markets (Glick, 2017).

Big Data of whatever size, velocity, and variety of data set requires new tools in order to compute. Although the data volume may be considered Big by today's standards, it is very likely to be the norm in the future perspective (Runciman and Gordon, 2014). This is precisely the reason why the word "Big Data" may not be appropriate and experts expect that the word "Big" will be dropped as the description fails completely as the "big number of connections" between people, places and things that are the actual valuable element of Big Data.(Baker and Gourley, 2014).

\section{Smart Data}

The literature introduced the term "Smart Data" around 2009 (Fisher, 2009) expressing the use of all relevant data for bringing value and support for decision making (Marr, 2015). Generally, there are two types of Smart data which are often discussed by academic and practitioners. The first is information collected by sensors and send to a collection point and acted upon before it is sent to analytics platform. Such data is sourced from smart sensors and is often used for 'Internet of Things' (IOT) systems. The second is Big Data that has been processed and is waiting to be turned into actionable information. As proposed by Khakimullin (2018), data coming and going to smart sensors will be called 'Sensor Data' whereas the term 'Smart Data' refers to Big Data that has been transferred to useful and actionable data.

Smart data is defined as the data that is transformed into information for decisionmaking and action cycle in that different data sources are brought together, filtered, analysed, and correlated to be able to deliver actual information which enables companies to decide or 
take actions. Therefore, Smart Data has to be seen as a set of technologies and processes including the structures associated with it that enable the companies to deliver value of the existing data.

Smart data is one of the key foundations of business intelligence (Lafrate, 2015), whereas Big Data is more focused on collection of data volume, variety, and velocity, Smart Data however, focuses on bringing actual value to the business. Therefore, Smart Data only contains all kinds of relevant data which have been already filtered, analysed and embody the framework for the actual decision-making process (Lafrate, 2015). According to Jähnichen (2015) Big Data is the rare material which needs to be refined to Smart Data, as such, Big Data may be considered of limited significance unless it has been transformed to Smart Data. In addition, the work of García-Gil et al (2017) lead to similar findings where they discovered that no matter the size of the Big Data sets, it only became of use and have a real impact once it has been transferred to Smart Data. According to Hardawar (2017) a perfect example for the efficient use of Smart Data and the interaction of data and the real world is the google lens which uses huge databases, links all information together, and provide consumers with the required information, sights, or products, by simply scanning the objects with the google lens. Smart Data can also be used to set the pricing based on the generated data which allows price management flexibly and efficiently through intelligent and adaptive incentive mechanisms (Niyato and Thai Hoang, 2016). Referring to the use of Smart Data for pricing Sen et al (2014) highlights the fact that Smart Data pricing is already the basis for several industrial sectors including airline companies, car rentals, big online players like Amazon and will spread out to all industrial sectors.

\section{From Big Data to Smart Data}

According to Coffey (2016) in 2020 the volume of all data stored will have a size of forty Zettabytes which equals sixty times the number of all sand grains on all beaches worldwide. Moving from Big data to Smart data and make this huge volume of data business relevant, device, analytics, and domain expertise has to be conducted, as illustrated in in Figure 1. Device expertise consists of technical specialties and knowledge such as mechanical structures and sensor measured variables. Analytics expertise analyses the available data and creates an architecture for processing the data and domain expertise which consists of knowledge and data of market drivers, customer needs, and product cycles convert big data to Smart Data.

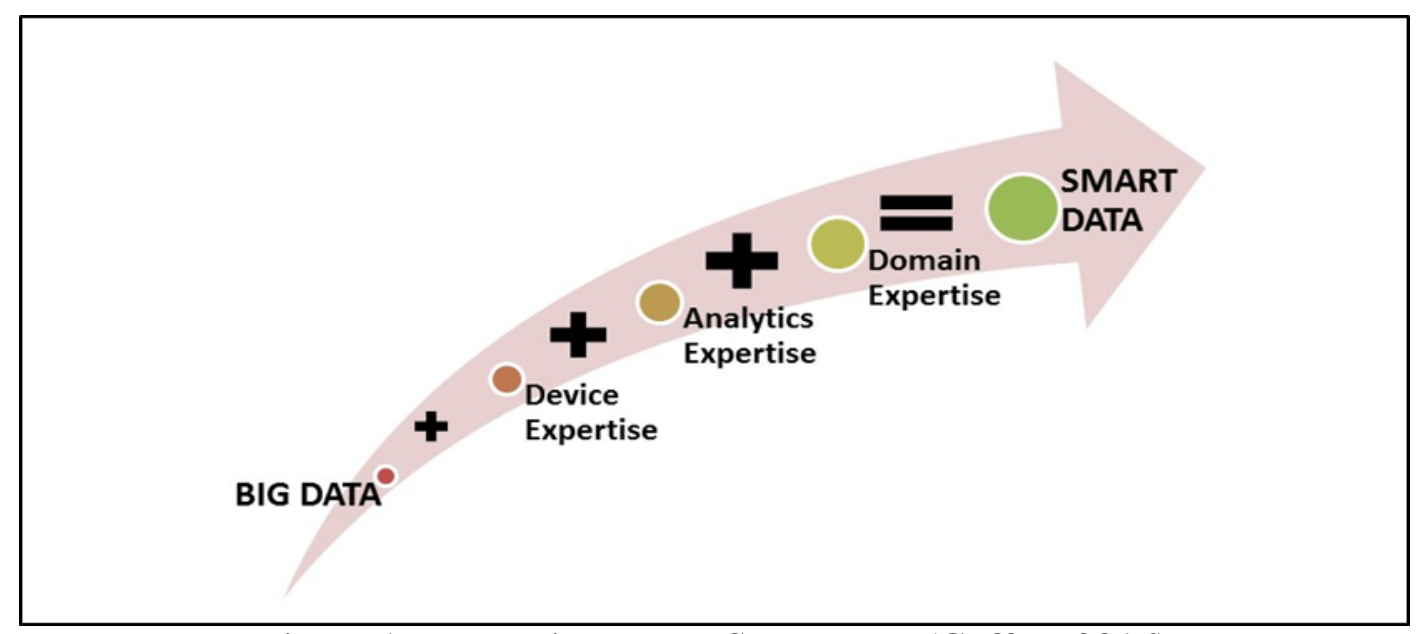

Figure 1: From Big Data to Smart Data (Coffey, 2016) 


\section{Competitive Advantage through efficient use of data}

According to Wheelen and Hunger (2012) and Clegg et al (2011) good business strategy aims to improve the competitive position of the company's products and services within the target market or segment. Considering the work of Porter (1985) on competitive strategies, Rayner (2017) is of the view that efficient use of data will not only lead to competitive advantage but also to efficient and innovative solutions and products. Further, the agility is an essential asset for a company to efficiently adapt to the changing market demand through organizational changes (Argyris and Schön, 1978; Senge P. M., 2010; Kotter, 2014) and adapting to cultural demands (Hofstede, 2004) by using an efficient and agile price setting (Teece et al., 2016) to ensure competitive advantage. The playground for competition is now global and the required respond rate for customer demands is more agile, hence Kotler et al (2016) strategies could provide a number of useful options for company's who wish to survival and success. Therefore, one of the major requirement for Smart Data to lead to competitive advantage and improvement of the business performance is that the data is generated with a required level of speed (Drucker, 1964; Culp et al., 2016) to enable the business to adapt to customer requirements quickly (Loeb, 2014; Aghina et al., 2015; James, 2015; Purkayastha and Sharma, 2016) and that the data is of value supported by high level of accuracy and reliability (Coffey, 2016). To ensure sustainable strategic value and survival in the competitive landscape of rapid change, companies are expected to develop dynamic capabilities for adapting, integrating, and reallocating existing resources in order to match the needs of the changing environment (Karimi and Walter, 2015). Creating the ability to use these dynamic capabilities leads to a strategic agility which allows companies to recognise and capitalise from opportunities that lead to competitive advantage on time (Sambamurthy et al.2003). According to Ransbotham and Kiron (2017) strategic value derives from analytics. To gain real strategic value it is essential that companies are moving from general-purpose to specialized analytics especially optimized to address specific measures. Moreover, they suggest that organizational silos have to be eliminated to coordinate data sharing and analytics across functional boundaries.

\section{Data Driven Decision Making}

According to Thorstad and Wolff (2018) the way that people think about the future is the most relevant factor when people are making future-oriented decisions. However, social factors and variety of different and available information have an impact in the way people make decisions. Jansen et al. (2017) is of the view that organizations are searching for ways to use the power of big data more efficiently to improve their decision making. Despite its significance, the impact of Big Data on decision-making quality has received limited attention in the literature. To contextualize data and make it a valuable source in the decisionmaking process contractual governance mechanisms are required to ensure the quality as the challenge is not only the data size but also factors like liability of data, the heterogeneity of data, and constantly changing data sources.

\section{Strategic Approaches to Smart Data}

Gartner (2015) predicted that up to 60 percent of all Big Data projects will not go beyond piloting phase until the year 2017. The main reason for this failure is that a successful advanced analytics strategy is much more than only acquiring the right tools. The key is to change the mind-sets and culture within a company and to be creative in search of success. 
Further, there are four key initiatives which ensure a successful Smart Data Project implementation. According to Gartner (2015) the first initiative is to choose a business problem that offers an initial win. This means to concentrate on a problem which has the biggest impact or the quickest payback. This can be daily operational decisions, planning process, or strategic topics. The higher the uncertainty and complexity of data involved, the better the chances for success of the implementation.

The second initiative consists of outsourcing or purchase packaged apps in the absence of advanced analytics and expertise. The majority of companies assume their current way of having own Business Intelligent teams dealing with all aspects of Big Data including their implementation allows further $t$ capabilities internally. However, there is another option for organizations that lack of internal skills to build advanced analytics themselves to use external service providers who deal with the advanced analytics applications to show the value of advanced analytics expertise for a particular problem.

The third and very crucial initiative is to identify stakeholders within the organization that need to be convinced of the value of advanced analytics. These might be the decision makers or the people who have to carry out the actions. Besides selling an attractive business case, it is more challenging to change people's beliefs and to make them understand why they might have to change their thinking. Due to that the success of advanced analytics is to not only communicate the value but also change the company culture to a data driven one.

The fourth and final initiative is to decide which skills and tools needs to be develpoed internally. According to Gartner (2015) the best in class analytical companies have own internal solutions but it may not be the right way to build up capacities internally for the start but use external resources.

Mac Innes (2017) who generally agrees with the work of Gartner (2015) is convinced that the fact that the data volume and sources are gaining continuously it encourages companies to search for solutions and to make sense of the data and sorting important available data from less important data. In addition, Mikalef et al. (2016) created a strategic framework to point out the most relevant factors to gain strategic relevance through big data. Figure 2 displays this framework. Based on their findings the first and most important factor to reach competitive advantage is IT competencies within a company which include the IT resources like infrastructure, skills, relational IT resources and data storage, and efficient data handling. The second key factor is organizational capabilities and business strategy. This also includes IT enabled dynamic capabilities like sensing, learning, coordinating, integrating, and reconfiguring. However, the framework may be criticized for lack of references to strategic aspects, target setting, soft skills, and implementation phases.

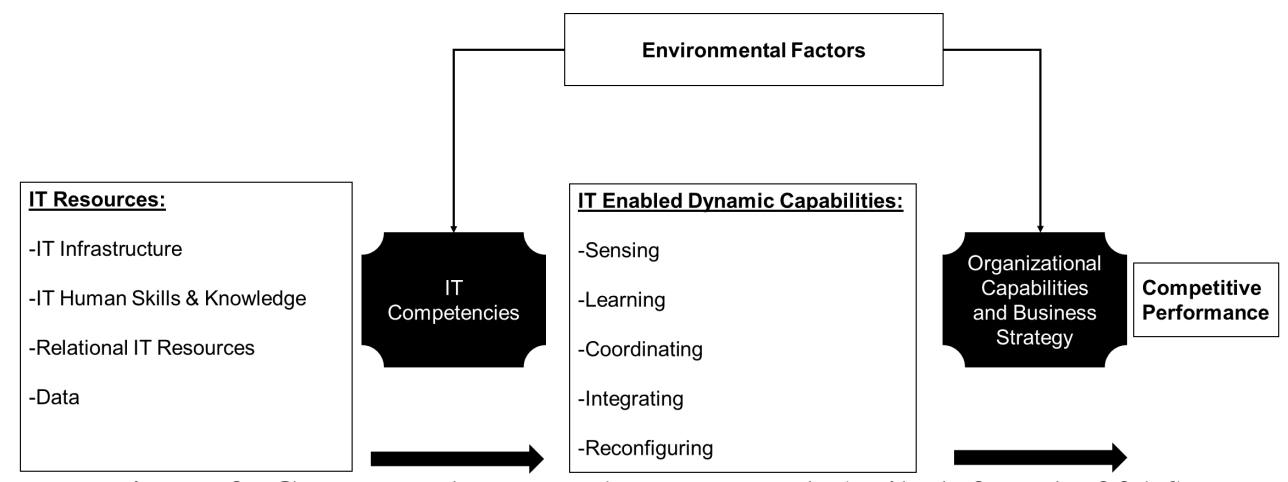

Figure 2: Conceptual Research Framework (Mikalef et al., 2016) 


\section{Smart Data and Business Intelligence}

According to Vinnakota (2012) Big Data and Smart Data applications are the successor of traditional business intelligence (BI) tools and bring major improvements. Whereas the scope of traditional BI is limited to structured data, the fact is that over $90 \%$ of today's data is unstructured, consequently traditional BI tools leave out over $90 \%$ of relevant data which can be taken into consideration with Smart Data applications. Based on that, traditional BI is left behind by forward-looking businesses that are keen to gain competitive advantage from unstructured business data floating around, within, and beyond their enterprise. While traditional BI was created to give the management a good overview of the customer performance in different areas including Finance, Sales, Human Resources, Marketing, IT, and purchasing, Smart Data analytics is aiming to provide a tool to drive actual decisions and predictive analytics taking all relevant data into consideration (Marr, 2015). Figure 3 illustrates the difference between the classical BI and Smart Data.

\begin{tabular}{|l|l|l|}
\hline Factors & Traditional BI & Smart Data \\
\hline $\begin{array}{l}\text { Speed of Data } \\
\text { processing }\end{array}$ & $\begin{array}{l}\text { Primary while data input or } \\
\text { query }\end{array}$ & $\begin{array}{l}\text { From parallel processing to } \\
\text { streaming }\end{array}$ \\
\hline Data Updates & Daily/multiple times daily & Real Time/Near Time \\
\hline Type of Analytics & $\begin{array}{l}\text { Easy to mid complex queries } \\
\text { or analytics }\end{array}$ & Up to advanced analytics \\
\hline Data Volume & Smal to mid sized & Huge data sets possible \\
\hline Use Cases & $\begin{array}{l}\text { E.g. General Reporting for } \\
\text { Finance, Marketing, Sales, }\end{array}$ & $\begin{array}{l}\text { E.g. Advanced analytics, Text } \\
\text { mining }\end{array}$ \\
\hline
\end{tabular}

Figure 3: Comparison Traditional BI and Smart Data

\section{Smart Data and Artificial Intelligence}

Artificial Intelligence is a sub-field of computer science with the target of machines being and acting human-like and autonomous. Tasks which would normally require human intelligence such as visual perception, speech recognition, decision-making and translation of languages, are all fields where Artificial Intelligence (AI) can act autonomous without human interactions (Marr, 2018).

Most businesses would like to capitalise from the opportunities provided by AI, however, irrespective of the purpose of AI, smart data is required to enable AI to become intelligent. The main difference between Smart Data applications and Artificial intelligence is that applied AI enables computers to make decisions on their own (Welsh, 2019), while Smart Data frameworks propose actions to the human user but the decision making is still in the power of the human not in the hands of the computer.

In fact, the authors of this article have the conviction that AI may not be able to deliver some of its promises when considering decision making. For example: there are three leading competitors on similar positioning, similar strategies, similar sizes and all using similar AI concepts. In case the market signs would give to all the AI systems the signal all three companies would react in the same way and competitive benefits would not be realised and other competitors may benefit from the action of the three main players. In contrast, using Smart Data applications the systems would propose a certain reaction to the market signs and the responsible department of the respective company can still evaluate in which way this proposal makes sense or not. The combination of AI and Smart data would support 
analytics, correlations, patterns, taking environmental changes into consideration. However, the above together with available technologies such as cloud and emerging technologies provide significant opportunities for exploitation of data in the future.

\section{Framework for advanced customer analytics}

The aim of customer analytics frameworks are to derive findings and knowledge to answer questions in a better manner. Fulfilling or even exceeding the customer requirements is one of the key elements when ensuring sustainable competitiveness in any industry (Harrigan, 2017). In order to use Data in the context of Business relations efficiently a framework is essential. There is only a view publication which investigate frameworks for using data efficiently. Kitchens et. al. (2018) published a detailed research in the Journal of Information Systems which dealt with advanced customer analytics, in particular he investigates the strategic value through integration of relationship-oriented Big Data. This section is mainly based on Kitchens et. al. (2018) but takes variety of publications and findings into consideration as well.

Kitchens et. al. (2018) proposed a framework for implementing advanced customer analytics solutions, including a set of constructs that may can be used to understand and predict consumer behaviour in a better way. The design of the framework, method, and instantiation is primarily related to the theory of relationship marketing frames with customers not a set of discrete transactions bit as relational exchange. Relationships with customers provide a source of sustainable competitive advantage and strategic value for the company. In order to make to make the framework helpful, the following factors have to be a part of the framework (Kitchens et al., 2018):

- A rich set of relationship-oriented constructs to guide the identification and acquisition of valuable data for advanced customer analytics

- A principled, flexible, versatile, and predictive model for extracting value from data constructs

- Value-based evaluation metrics for action and outcome-oriented cost/benefit analysis

- Construct evaluation leading to value-justified integration and data management investments in IT infrastructure to create a foundation for integrated data for analytics

- A portfolio of advanced customer analytics capabilities supported by IT-enabled agility for providing strategic value through enhanced customer lifetime value and customer equity.

This Framework incorporates a wide number of aspects which are important for customer analytics. However, the author of this study believes that fundamental aspects like brand power, brand heritage, and a customer segmentation based on valuable segmentation criteria are missing. In addition, missing out such important information in the analytics phase, will have a significant negative impact on the quality of the predictions using the predictive model. 


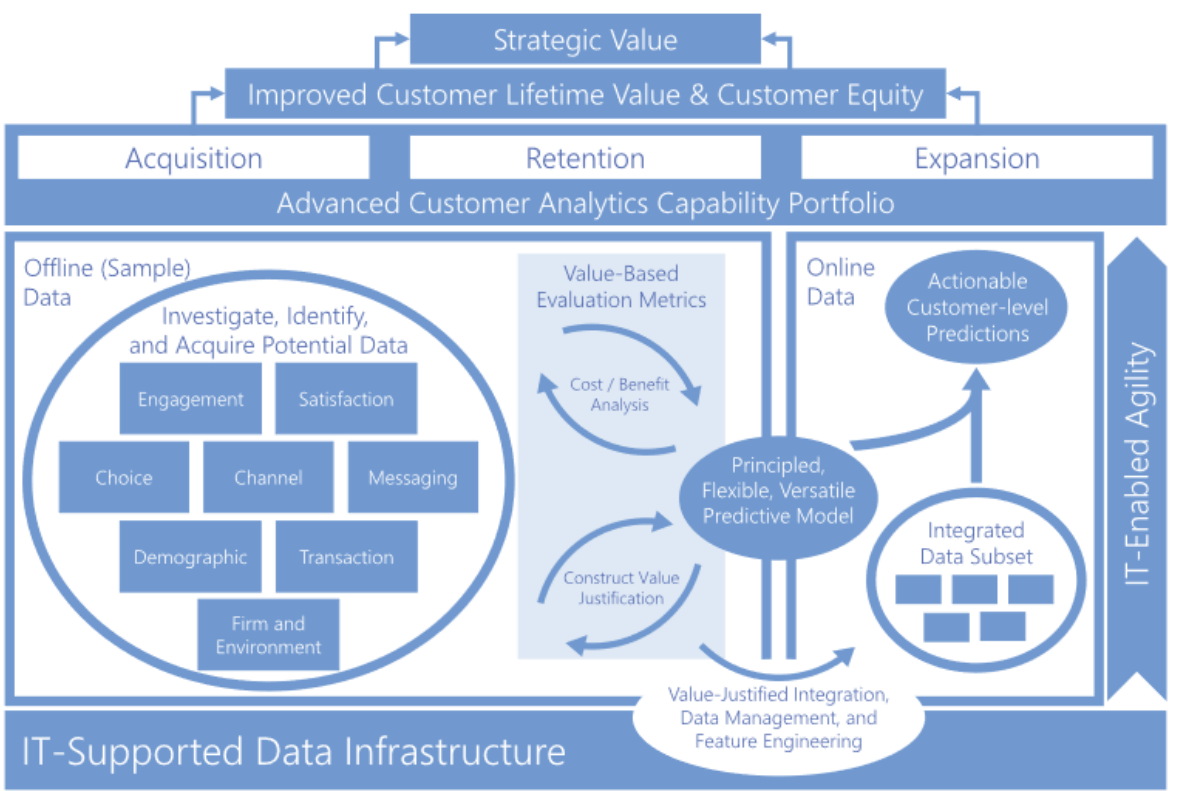

Figure 4: Advanced Customer Analytics Framework (Kitchens et al., 2018)

\section{Advanced customer analytics constructs}

In intending to guide the identification and acquisition of beneficial data sources Kitchens et al. (2018) developed a comprehensive and generalized set of potential construct categories. Some of these have rarely been used to predict customer behaviour as the integration is difficult. They suggest that only a synergistic approach which takes data from a rich variety of sources into consideration is beneficial to create advanced customer analytics. This model is unlikely to take all further intangible customer characteristics such as expertise, risk affinity, and technical self-efficacy into consideration (Bolton et al., 2004). The following factors are still solid characteristics in order to build a valid advanced customer analytics construct.

\section{Transaction}

The characterization Transaction with regards to customer relationship is the most basic one. The most used factors trying to predict customer behaviour are measurement of frequency, recency of monetary value involved in the transaction (Petty and Cacioppio, 2018). It may also include more details such as promotion, discount levels, payment types, or specific items purchased (Kitchens et al., 2018).

\section{Demographics}

Demographics are basic information about the customer. Combining transaction with demographics is the starting point for every customer analytics construct. However, relationship marketing studies have discovered that the demographic background significantly influence the baseline expectations which is directly linked to satisfaction, repurchase intention, and purchase behaviour (Mittal and Kamakura, 2001; Lalwani and J., 2018).

\section{Engagement}


Customers engage with companies in many ways beside the purchase transactions. Depending on the type of engagement, conclusions about future behaviour may be drawn (Beckers et al., 2018). Such engagements may be the visit of the corporate website, opening an email, contact customer service, visiting a forum, or posting a review online. In general engagement shows the interest of the customer to continue the relationship with a company (Kitchens et al.,2018). The level of sophistication of the ability to collect, measure, and analyse data is wide spread cross the different companies. Especially variables which are not controlled by the company itself such as social media tend to be problematic in terms of handling for the majority of companies (Beckers et al., 2018; Trkman and Trkman, 2018). As the capabilities improve constantly, customer engagement has the potential to become a valuable resource for advanced customer analytics. The core challenge consists of the integration with other customer data for analysis purposes (Kitchens et al.,2018).

\section{Satisfaction}

A number of empirical studies have shown that increasing satisfaction leads to an improved customer retention and increasing customer life-time value (Grover et al., 2018; Kumar and Reinartz, 2018). Beyond satisfaction, there are other related perceptual constructs like commitment, loyalty, trust, and the perception of the company which are strongly connected with satisfaction and how customer feel and think about a firm (Beyari and Abareshi, 2018). The core challenge with satisfaction and related perceptions is the difficulty in measuring individual customer's satisfaction. The majority of studies examine these perceptions on sample base surveys intending to explain customer relationships or measuring the entire market share rather than making individual-level predictions (Kitchens et al., 2018).

\section{Choice}

Another core parameter is the customer's first and subsequent choice of services or products purchased, especially if the products of choice differ horizontally significantly. The categories or products purchased can be and is an indicator for the level of trust or interest for a particular company and the likelihood of cross buying of certain product groups (Garrette et al., 2018; Kitchens et al., 2018).

\section{Channel}

The channel through which the customer acquires products or services and continues to interact with the company provide important information about the customer and the relationship with the company (Kitchens et al., 2018). A mix of various channel interactions may lead to a positive effect on the customer loyalty (Ascarza, et al., 2018). In addition, studies have found that customers using digital channels tend to be more loyal and active due to self-selection effects and greater opportunities to form connections with the company (Kitchens et al., 2018). Moreover, it is crucial to take into consideration that different channels may attract different customer groups (Ascarza, et al., 2018).

\section{Messaging}

The communication the customer receives from a company may impact on the future behaviour of the customer in relation with the respective company. The majority of companies focus on messaging in the context of informing customers about promotional activities to encourage the customer to a purchase. However, relationship building messaging which focuses on the customer's view of the company may not be game changer for the short-term but a very rich tool ensuring a long-term relationship (Kumar, 2018). The 
mode and quantity of communications received may also impact customer behaviour. In both cases, too little and too much communication can be harmful.

\section{Firm and environment characteristics}

The characteristics of a company and the market the company is operating in is the basis for customer's relationship with the company. Factors like brand equity, perceived fairness of the company, pricing policy, and corporate ethics have a major impact on the customer's perception and relationship with the company (Zietsman et al., 2018). In addition, characteristics like competition, market share, and perceived complexity influence the customer's view on the company (Kitchens et al., 2018). This construct incorporates a wide number of aspects which are important for customer analytics. However, the author of this study believes that fundamental aspects like brand power, brand heritage and a customer segmentation based on valuable segmentation criteria are missing.

\section{Characteristics of a rich predictive Model}

Relationship-oriented data can be in the body of many different formats, structured and unstructured. However, traditional machine learning methods are limited in the complexity of data which can be analysed. According to Kitchens et al (2018) in order to ensure full leverage of available value within each construct category for producing customer insights, a customer analytics framework should employ a predictive model that is:

- Capable of theory-driven prediction to exploit the nuances of relationship-oriented data

- Flexible in accommodating complexity of a wide variety of data constructs of different formats

- Versatile in application to a variety of customer analytics initiatives.

Each of the above characteristics is embodied by Kernel-based learning methods, allowing theory embedding via customized kernel functions, incorporation of structured and unstructured data, and adaptability to a wide range of tasks (Chiang et al., 2018; Kitchens et al., 2018) making it feasible to effectively represent the complexities of customer behaviour.

\section{Value-Based evaluation metrics}

Working with a huge volume of data and creating an advanced customer analytics framework, a clear guideline and for directly measuring the value of an analytical solution is necessary. Such guidelines are an absolute must working with advanced customer analytics as the essential support for management of the volume, variety, and velocity of required data can be costly and have to be justified (Kitchens et al., 2018). Reviewing the relevant literature on the value of big data analytics (Marr, 2015; Mikalef et al., 2017) and how to deal with information systems (Laney, 2015), the core steps for creating a valuebased evaluation matrix include:

\section{Identify Potential Actions}

The intermediate outcome of customer analytics are predictions regarding the customer behaviour. However, the pure prediction is not of any value as the value creation is only taking place if the predictions are leading to decisions or actions within a company. Only in cases were predictions lead to decisions or actions there is the chance of value creation (Delen et al., 2018; Vassakis et al., 2018). Those decisions and actions can be linked with 
topics like improvement of customer relationship, influencing the purchase behaviour of the customer or defining define cost reduction measures. Based on this it is essential that every customer analytics has the final goal of creating value driving decisions and actions. As a first step it is essential to reflect all in the company existing customer analytics and eliminate those which cause manual work without creating actual value and do not drive decisions and actions (Kitchens et al., 2018). Grover et al (2018) argues that the most important strategic options to consider before and during the design of customer analytics is to critically review if the resulting options really create value and drive relevant decisions and actions within the company.

\section{Determine Action Value}

After the potential outcomes of the customer analytics are reflected and linked actions and decisions are taking into consideration, the proposed actions have to be further analysed per customer with regards to benefits, risks, costs, and resources required. This process is very similar to creating a cost matrix for cost sensitivity analysis. All costs and benefits have to be assigned to correct, incorrect, positive and negative predictions (Kitchens et al., 2018). All costs and benefits have to be reflected including managerial and marketing cost savings which would be realized in churn case of customers and revenue gains for the remaining customers (Shmueli and Koppius, 2011). Determining the entire range of values for potential actions requires assumptions based in part on experience and analysis of historical activities (Nagle and Müller, 2017).

\section{Define Boundary}

Before finally implementing the value-based evaluation matric, it has to be defined which customers are included in which action. For instance, companies with a high likelihood for churn may not be included in a marketing campaign. Every model implemented in the context of an advanced customer analytics solution will only be able to provide estimations or the likelihood of a certain outcome for each customer. Based on this it is an absolute must to carefully consider the findings and how to determine what share of customers will receive specific potential actions (Shmueli and Koppius, 2011).

\section{Generate Final Metrics}

Finally, the actions, value, and boundaries determined are in this stage are combined to create a complete value-based evaluation metrics, which is critical in later stages for evaluating constructs and models, guide data management, integration, real-time feature engineering efforts, and demonstrate potential return on investment. For each combination of potential action and actual outcome, a net ratio of cost and benefit is defined and applied to all predictions. To reach the total expected value the number of customers which are above the boundary are multiplied with the per customer value (Kitchens et al.,2018). Generally, this evaluation is a straight forward way to evaluate how beneficial analytic frameworks may be. Based on the belief of the researcher this part of the study of Kitchens et al. (2018) is the most valuable part.

\section{Value-Justified Data Management, Integration and Feature Engineering}

The most important aspect to be considered for any big data analytic initiative is the costs creation for data management, integration efforts, and real-time feature engineering (Grover et al., 2018). The core essence dealing with any big data analytical framework is to evaluate each potential construct with regards to the value-based metrics identified earlier, enabling 
the IT department to focus only on the most valuable data once in order to focus and gain speed (Mendes et al., 2018). They suggest to use the add-in and leave-out approach to quantify the individual value for each construct. Therefore, all the existing constructs will be in the first step excluded. Only the most basic models will remain which do not cause additional investments and are anyway available. Now the actual evaluation begin is and the decision has to be taken which analytics is bringing significant value and should receive investments in data management, integration, and real-time feature construction. These actions result in value-justified investments in IT infrastructure supporting an agile deployment of advanced customer analytics.

\section{Portfolio of Advanced Customer Analytics}

According to Kitchens et al. (2018) the ultimate aim of the framework is to design a portfolio of customer analytics applications which are supported by value-justified IT infrastructure and enables agility. This portfolio has to include applications across customer acquisition, retention and expansion. Using the analytics of these different dimensions might improve the customer lifetime value, customer equity, creating strategic value and leading to sustainable competitive advantage.

\section{Research Methodology}

Due to dynamic nature of the business environment the use of literature review as a research method is supported by many including; Harrigan (2017), Kitchens et al (2018), Marr (2018), Mikalef et al (2016), and Welsh (2019). Benefiting from the professional experience of the author, the review concludes with a conceptual framework.

\section{Results and Analysis}

The proposed conceptual framework in figure five consists of four hierarchal levels which are Strategy, Resources, Operations and Design. In case there are mismatches in the hierarchical levels there is a high likelihood that the superior levels will not be able to compensate this mismatch and the whole concept will not deliver and the competitive advantage may not be realised. The framework is influenced by the work of Mikalef et al., (2016) the Conceptual Research Framework, and Kitchens et al., (2018) Advanced Customer Analytics Framework. The following sections describe each level of the framework; 


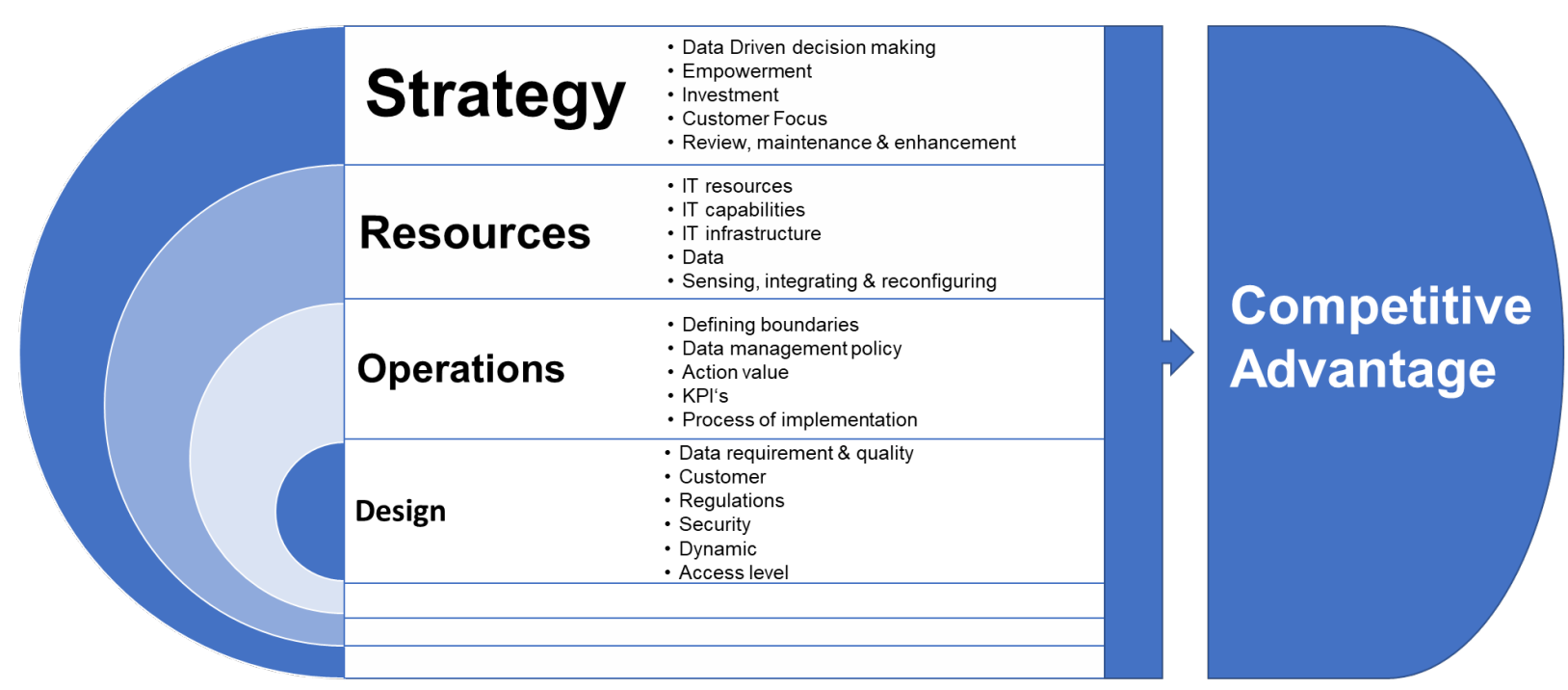

Figure 5: Conceptual Framework of Smart Data

\section{Strategy}

Every project has to be based on a strategic background which is the first hierarchical level in this framework. It is essential that the top management is willing to change their behaviour towards data driven decision making and therefore allow the company to question overall decisions in case the data analysis would lead to different assumptions. In addition, the top management has to have the conviction of empowering employees and actively transferring power to people to be able to drive the change. Further, the company has to be committed to the required investment for setting up the IT infrastructure, allocate resources, emerging technologies, and awareness of the fact this is a long term investment for the future of the company and returns are not achieved in a short period of time. Moreover, companies have to believe in the value of being truly customer focused in order to have a true purpose. Finally, the strategy has to be review, maintain, and enhanced in order to adapt to changing environment and expectations.

\section{Resources}

For companies to leverage the benefits of Smart Data, certain resources are essential. The foundation is IT resources which are the basis for starting any Smart Data concept. As dealing with Smart Data is not a standard IT capability, those capabilities have to be built up in order to drive Smart data projects. Further, the IT infrastructure has to include both physical and digital elements, making Smart Data analytics an integrated part of the IT environment. In addition; relevant data set has to be collected and stored and consideration must be given to change of culture, information sharing, data quality, governance, and security.

\section{Operations}

The third hierarchical level consists of the operations. Frist of all boundaries have to be defined per employee group. What is expected from each employee, which decision can the employee take on their own and which ones need further approval. This goes hand in hand with a data management policy which in addition defines how to deal with data from legal perspective but also within the internal terms and conditions. Further, for every Smart Data framework which is requested to be implemented the action value has to be clearly defined. Which actions will be taken in case of different outcomes of the analysis? In case the 
outcomes would not influence and action taken within the company there is a high likelihood that the requested project is not of high value. After a project is identified to bring action value, the relevant KPI's have to be defined in order to create a measurable framework, and finally the process of implementation and integration has to be defined.

\section{Design}

In this level all data requirements have to be set in place in order to decide which data to be selected and which data to ignore. Normally it is expected that the data has to be of high standards in order to allow accuracy and reliability. In case of using customer data the customers have to be consulted and a written agreement of data use has to be documented. Further, national and international laws have to be taken into account to ensure legal conformity. The security of data as well plays and important role as confidential data should not be accessible to unauthorised any entities. Moreover, the dynamic of data updates should be automated with adequate timeframe depending on the type of data. Finally, the access levels have to be defined to clarify who should have access to which kind of data to only give access to critical data to a defined set of people.

\section{Research Limitation and Future Direction}

Whilst there are limited publications in the subject area under study, Smart Data covers a wide range of topics, hence, focus on specific parts of Smart Data such as Construction of Smart Data analytics for a specific area or the implementation of Smart Data Analytics for a specific area would have been beneficial. To further understand the impact of Smart Data on business performance, future work may be conducted at both theoretical and practical levels. This study suggests a number of opportunities for future research including the implementation process of Smart Data, analysis of the impact of Smart Data implementation on company performance, and the benefits and challenges associated with the successful implementation of Smart Data.

\section{Conclusions}

This paper identified the differences of Big Data and Smart Data, how Big Data can become Smart Data and how this can is connected to data driven decision making leading to possible competitive advantage. The review suggest that there are different interpretations of Big Data and Smart Data and how the efficient use of data will lead to business performance improvement and competitive advantage. In addition whilst the existing strategic approaches to Smart Data provide useful information in support of the same, they are limited in relation to inclusion of all required factors. The proposed framework incorporates all the required factors within strategic, resources, operations, and design hierarchical levels. Due to limited number of publications on the impact of data on business performance and competitive advantage, the paper contributes to knowledge and the proposed framework could assist companies to benefit from a manageable and practically driven approach on how to deal with Smart Data efficiently and effectively for enhanced business performance and competitive advantage

\section{References}

Aghina, W., De Smet, A. and Weerda , K. (2015). Agility: It rhymes with stability. McKinsey Quarterly.

Argyris, C. and Schön, D. A. (1978). Organizational Learning: A theory of action perspective. Reading. 
Ascarza, E., Neslin, S. A., Netzer, O., Anderson, Z., Fader, P. S., Gupta, S. and Schrift, R. (2018). In Pursuit of Enhanced Customer Retention Management: Review, Key Issues, and Future Directions. Customer Needs and Solutions, 5(1-2), 65-81.

Baker, P. and Gourley, B. (2014). Data Divination: Big Data Strategies. Cengage Learning. Boston.

Beckers, S. F., van Doorn, J. and Verhoef, P. C. (2018). Good, better, engaged? The effect of company-initiated customer engagement behavior on shareholder value. Journal of the Academy of Marketing Science, 46(3), 366-383.

Beyari, H. and Abareshi, A. (2018). An Empirical Study of How Social Influence Impacts Customer Satisfaction with Social Commerce Sites. IRICT 2018: Recent Trends in Data Science and Soft Computing, Springer, pp. 973-984.

Bolton, R. N., Lemon, K. N. and Verhoef, P. C. (2004). The theoretical underpinnings of customer asset management: A framework and propositions for future research. Journal of the Academy of Marketing Science, 32(3), 271-292.

Canitoa, J., Ramos, P., Moro, S. and Rita, P. (2018). Unfolding the relations between companies and technologies under the Big Data umbrella. Computers in Industry, 99, 1-8.

Chiang, R. H., Grover, V., Liang, T. P. and Zhang, D. (2018). Special Issue: Strategic Value of Big Data and Business Analytics. Journal of Management Information Systems, 35(2), 383-387.

Clegg, S., Carter, C., Kornberger, M. and Schweitzer, J. (2011). Strategy Theory and Practice. Sage Publication Ltd. London.

Coffey , L. (2016). "Smart Data - What is it and How it is Different From Big Data?, available at: http://digitalcommunity.mit.edu/docs/DOC-1232 (accessed 14 February 2020).

Culp, K., Eastwoodx, C., Turner, S., Goodman, M. and Ricketts, K. G. (2016). Using a SWOT Analysis: Taking a Look at Your Organization. Community and Economic Development Publications. Kentucky.

Delen, D., Moscato, G. and Toma, I. L. (2018). The impact of real-time business intelligence and advanced analytics on the behaviour of business decision makers. International Conference on Information Management and Processing, IEEE, London, pp. 49-53.

Drucker, P. (1964). Managing for Results: Economic Tasks and Risk-Taking Decisions. Harper and Row. New York.

Fisher, T. (2009). The Data Asset: How Smart Companies Govern Their Data for Business Success. John Wiley and Sons. Hoboken.

Garrette, B., Phelps, C. and Sibony, O. (2018). Structure the Problem: Analytical Frameworks. Cracked it!, pp. 95-116.

García-Gil, D., Ramírez-Gallego, S., García, S. and Herrera, F. (2017). A comparison on scalability for batch big data processing on Apache Spark and Apache Flink. Big Data Analytics, 2

Gartner. (2015). Gartner Says Business Intelligence and Analytics Leaders Must Focus on Mindsets and Culture to Kick Start Advanced Analytics. Gartner Business Intelligence and Analytics.

Glick, B. (2017). UK tech must go forward with confidence. Computer Weekly, 18-32.

Grover, V., Chiang, R. H., Liang, T. P. and Zhang, D. (2018). Creating Strategic Business Value from Big Data Analytics: A Research Framework. Journal of Management Information Systems, 35(2), 388-423.

Hardawar, D. (2017). Google Lens offers a clear view of the company's future. Adding vision to its growing AI prowess is just the start. Personal Computing.

Harrigan, K. R. (2017). Strategic Flexibility and Competitive Advantage. Oxford Research Encyclopedias of Business and Management.

Hofstede, G. (2004). Cultures and Organizations: Software for the Mind. McGraw Hill Professional. Jähnichen, S. (2015). From Big Data to Smart Data - Challenges for the economy. Smart Data, 1, 13.

James, S. (2015). What price Agile? How to establish the right pricing model. Coputer World UK.

Jansen, M., van der Voort, H. and Wahyudi, A. (2017). Factors influencing big data decision-making quality. Journal of Business Research, 70, 338-345.

Karimi, J. and Walter, Z. (2015). The role of dynamic capabilities in responding to digital disruption: A factor-based study of the newspaper industry. Journal of Management, 32(1), 39-81. 
Khakimullin, A. (2018). "Big Data vs. Smart Data", available at: https://www.dataversity.net/bigdata-vs-smart-data/\# (accessed 12 February 2020).

Kitchens, B., Dobolyi, D., Li, J. and Abbasi, A. (2018). Advanced Customer Analytics: Strategic Value Through Integration of Relationship-Oriented Big Data. Journal of Management Information Systems, 35(2), 540-574.

Kotler, P., Berger, R. and Bickhoff, N. (2016). Strategy and Strategic Management: A First Basic Understanding. Springer. Heidelberg.

Kotter, J. P. (2014). Accelerate: Building Strategic Agility for a Faster-Moving World. Harvard Business Review Press.

Kumar, V. (2018). A Theory of Customer Valuation: Concepts, Metrics, Strategy, and Implementation. Journal of Marketing, 82(1), 1-19.

Kumar, V. and Reinartz, W. (2018). Customer Relationship Management: Concept, Strategy, and Tools. Springer. Heidelberg.

Lafrate, F. (2015). From Big Data to Smart Data. Hoboken: John Wiley and Sons.

Laguna, M. and Marklund, J. (2018). Business Process Modeling, Simulation and Design. CRC Press. London.

Lalwani, A. K. and J., J. W. (2018). How Do Consumers' Cultural Backgrounds and Values Influence Their Coupon Proneness? A Multimethod Investigation. Journal of Consumer Research.

Laney, D. (2015). Why and how to measure the value of your information assets. Gartner, pp. 1-22. Loeb, W. (2014). Amazon's Pricing Strategy Makes Life Miserable For The Competition. Forbes.

Lohr, S. (2012). The Age of Big Data. The New York Times.

Mac Innes, B. (2017). The big data project challenge. On discovering that many big data projects fail Billy MacInnes wonders how the industry can ensure more of them are successful. MicroScope.

Manyika, J., Chui, M., Brown, B., Bughin, J., Dobbs, R., Roxburgh, C. and Angela, B. H. (2011). Big data: The next frontier for innovation, competition, and productivity. McKinsey Global Institute.

Marr, B. (2015). Big Data: Using SMART Big Data, Analytics and Metrics to Make Better Decisions and Improve Performance. John Wiley and Sons. Hoboken.

Marr, B. (2018). The Key Definitions Of Artificial Intelligence (AI) That Explain Its Importance. Forbes Media LLC.

McAfee, A. and Brynjolfsson, E. (2012). Big Data: The Management Revolution. Harvard Business Review, pp. 59-68.

Mendes, E., Rodriguez, P., Freitas, V., Baker, S. and Atoui, M. A. (2018). Towards improving decision making and estimating the value of decisions in value-based software engineering: the VALUE framework. Software Quality Journal, 26(2), 607-656.

Mikalef, P., Framnes, V. A., Danielsen, F., Krogstie, J. and Olsen, D. H. (2017). Big Data Analytics Capability: Antecedents and Business Value. PACIS.

Mikalef, P., Pappas, I., Giannakos, M., Krogstie, J. and Lekakos, G. (2016). Big Data and Strategy: a Research Framework. Tenth Mediterranean Conference on Information Systems, MCIS, Paphos, pp. 1-7.

Mittal, V. and Kamakura, W. A. (2001). Satisfaction, repurchase intent, and repurchase behavior: Investigating the moderating effect of customer characteristics. Journal of Marketing Research, 38, 131-142.

Mougalas, R. (2005). What is Web 2.0? Tim O'Reilly Media.

Nagle, T. T. and Müller, G. (2017). The strategy and tactics of pricing: A guide to growing more profitably. Routledge. New York.

Niyato , D. and Thai Hoang, D. (2016). Smart data pricing models for the internet of things: a bundling strategy approach. IEEE Network, 30(2), 18-25.

Petty, R. E. and Cacioppio, J. T. (2018). Attitudes and persuasion: Classic and contemporary approaches. Routledge. New York.

Porter, M. E. (1985). Competitive Advantage: Creating and Sustaining Superior Performance. Free Press. New York. 
Purkayastha, A. and Sharma, S. (2016). Gaining competitive advantage through the right business model: analysis based on case studies. Journal of Strategy and Management, 9(2), 138-155.

Ransbotham, B. S. and Kiron, D. (2017). Analytics as a source of business innovation. MIT Sloan Management Review, 1-16.

Rayner, A. (2017). Smart Decision-Making and Productivity in the Digital World: The Case of PATAmPOWER. In E. G. Carayannis, and S. Sindakis, Analytics, Innovation, and Excellence-Driven Enterprise Sustainability, Palgrave Macmillan US, New York, pp. 207223.

Runciman, B. and Gordon, K. (2014). Big Data. Opportunities and challenges. BCS Learning and Development Limited. Swindon.

Sambamurthy, V., Bharadwaj, A. and Grover, V. (2003). Shaping agility through digital options: Reconceptualizing the role of information technology in contemporary firms. MIS Quarterly, 27,(2), 237-263.

Sen, S., Joe-Wong, C., Ha, S. and Joe-Wong, C. (2014). Smart Data Pricing. John Wiley and Sons. Hoboken.

Senge, P. M. (2010). The Fifth Discipline: The Art and Practice of the Learning Organization. Cornerstone Digital.

Shmueli, G. and Koppius, O. R. (2011). Predictive Analytics in Information Systems Research. MIS Quarterly, 35(3), 553-572.

Teece, D., Peteraf, M. and Leih, S. (2016). Dynamic Capabilities and Organizational Agility. California Management Review, 58(4), 13-35.

The World Economic Forum. (2012). Big Data, Big Impact: New Possibilities for International Development. Geneva.

Thorstad, R. and Wolff, P. (2018). A big data analysis of the relationship between future thinking and decision-making. PNAS, 20.

Tilly, C. (1980). The old new social history and the new old social history.

Trkman, M. and Trkman, P. (2018). A framework for increasing business value from social media. Economic Research, 31(1), 1091-1110.

Vassakis, K., Petrakis, E. and Kopanakis, I. (2018). Big Data Analytics: Applications, Prospects and Challenges. In K. Vassakis, E. Petrakis, and I. Kopanakis, Mobile Big Data, Springer, pp. 322.

Vinnakota, S. (2012). "Big Data Vs. Traditional Business Intelligence", available at: https://www.smartdatacollective.com/why-we-can-no-longer-afford-pit-big-data-againsttraditional-bi/ (accessed 10 February 2020).

Welsh, R. (2019). SMPTE Periodical - Defining Artificial Intelligence. SMPTE Motion Imaging Journal, 128(1), 26-32.

Wheelen, T. and Hunger, J. (2012). Strategic Management and Business Policy: Toward Global Sustainability. Pearson Education.

Zietsman, M. L., Mostert, P. and Svensson, G. (2018). Perceived price and service quality as mediators between price fairness and perceived value in business banking relationships: A micro-enterprise perspective. International Journal of Bank Marketing, 37(1), 2-19. 